\title{
Synthesis of Cresols on Zeolite
}

\section{Torosyan GH*}

Department of Chem-bio \& environmental technologies, Armenia

\section{Abstract}

The alkylation of sorpted on zeolite (Armenian natural clinoptilolite modified with Ba salts) phenol with methanol take place with formation of cresols. The proposal method can be used for recovering zeolite after phenol sorption also.

ISSN : 2688-8394

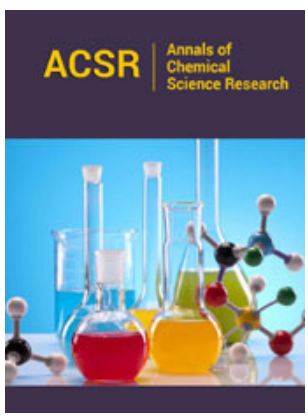

*Corresponding author: Torosyan GH, Department of chem-bio \& environmental technologies, Armenia

Submission: 眥 February 27, 2020

Published: 眥 March 12, 2020

Volume 2 - Issue 1

How to cite this article: Torosyan GH. Synthesis of Cresols on Zeolite. Ann Chem Sci Res. 2(1).ACSR.000526.2020. DOI: 10.31031/ACSR.2020.02.000526

Copyright@ Torosyan GH, This article is distributed under the terms of the Creative Commons Attribution 4.0 International License, which permits unrestricted use and redistribution provided that the original author and source are credited.

\section{Introduction}

The methylation of phenols is a very important industrial reaction. Industrially the phenol methylation is carried out by means of three types of processes:

A. Liquid-phase alkylation

B. Fixed-bed liquid-phase processes

C. Vapor-phase alkylation

It is known that methyl-phenols (cresols) are an industrial intermediate. In industry, their main source is coke production [1]. In practice, phenol methyl ether, more commonly known as anisole, is also widely used.

\section{Results and Discussion}

The industrial method for the synthesis of cresols is technologically complicated, since the synthesis is carried out in an environment of sulfuric acid. Such a strong aggressive environment requires the use of anti-corrosion, expensive equipment, and the process itself creates the possibility of the formation of acidic wastewater [1]. Here is present the results of studies on the use of the previously found effective sorbent for phenol from the water solution-Armenian natural clinoptilolite modified with Ba salts, for use it as a catalyst in the phenol alkylation reaction.

It was previously assumed [2] that in the described process either 0-alkylation of phenol takes place with the formation of alkyl phenyl ethers, which then, for example, in the case of anisole at high temperature, rearrange to cresol/Kursanov reaction or have direct hightemperature C-alkylation to a benzene core phenol [2].

$$
\mathrm{C}_{6} \mathrm{H}_{5} \mathrm{OH}+\mathrm{CH}_{3} \mathrm{OH}
$$

Heating of anisole under alkylation conditions leads to the formation of p-cresol, albeit with a low yield. Moreover, oxygen-alkylation products-anisole were not found in phenol methylation processes. The yield of phenol carbon-alkylation products increases in the presence of water. Based on these observations, it can be assumed that C-alkylation to the core takes place. Thus, these studies have shown the possibility of using phenol deposited on zeolite. The proposed method can be used for the disposal of harmful waste-phenol from sorbents. Phenol is a strong toxic substance- the maximum permissible concentration in water is $0.001-0.002 \mathrm{mg} / \mathrm{l}$ and in air $-0.005 \mathrm{mg} / \mathrm{l}[2]$.

\section{Experimental part}

Equipment and Chemicals: Phenol, methanol, cresols, zeolite-clinoptilolite was supplied by the National Polytechnic University of Armenia supplier. The reaction products were monitored by Gas-liquid chromatography (GLCh) with comparison supplied cresols. The reaction progress and purity of the compounds were monitored by Thin Layer Chromatography (TLCh) on SilufolUV-254 plates in an eluent was benzene-ethanol (2:1), and the display was performed using iodine vapor. 
Preparation of zeolite: Armenian natural clinoptilolite modified with Ba salts (Cl-Ba) [2].

The deposition of phenol on zeolite: Accurately weighed portions of $\mathrm{Cl}-\mathrm{Ba}$ were added to specific volumes of phenol in water, the initial concentrations of which varied. The mixture was thoroughly shaken for 6 hours. Next, the sample was left to stand. Adsorption is almost complete in the first 48 hours. Measurements were made of the refractive index of the solution before and after adsorption. The amount of phenol deposited on the zeolite was determined by a refractometric analysis method [2].

Phenol methylation on zeolite. Methanol was introduced into the flask of a vacuum-dried phenol- $\mathrm{Cl}$-Ba complex. The temperature of the reaction medium was raised to $250{ }^{\circ} \mathrm{C}$. The molar ratio of phenol: methanol=1:1. After $1 \mathrm{~h}$ of heating, the reaction mixture was cooled. The reaction products were isolated with diethyl ether and dried on $\mathrm{MgSO}_{4}$. After ether removal, a mixture of cresols (o, $\mathrm{m}$ and $\mathrm{p}$-isomers) was isolated in $35-37 \%$ yield. Transformation of anisole on $\mathrm{Cl}-\mathrm{Ba}$ at $200^{\circ} \mathrm{C}$. $1.1 \mathrm{~g}$ of anisole was heated for $1 \mathrm{~h}$ on sorbent. After cooling the reaction mixture, the reaction products were isolated with diethyl ether and dried on $\mathrm{MgSO}_{4}$. After ether was removed, distillation at $195-197{ }^{\circ} \mathrm{C}$ yielded $0.2 \mathrm{~g}$ of p-cresol (18\% yields).

\section{Conclusion}

The sorpted on zeolite phenol undergoes on methylation reaction with heating by methanol. In result formatted the mixture of cresols. The proposed method can be used after phenol sorption on zeolite for them recovering.

\section{References}

1. Fiegein H (2007) Cresols and xylenols in Ullmann's encyclopedia of industrial chemistry. Wiley-VCH, Weinheim, Germany.

2. Torosyan GH, Isakov AA, Aleksanyan AR, Hovhannisyan DN (2006) The phenol sorption from solution by aluminosilicates and its further chemical conversion 59(2): 53-59. 